\title{
A Clinical Study on Cutaneous Manifestations of Obesity
}

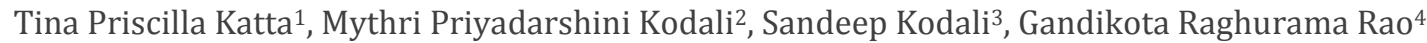

\begin{abstract}
${ }^{1}$ Associate Professor, Department of DVL, Apollo Institute of Medical Sciences, Hyderabad, Telangana, India. ${ }^{2}$ Assistant Professor, Department of Radiodiagnosis, GSL Medical College and General Hospital, Lakshmipuram, Rajanagaram, Rajahmahendravaram, Andhra Pradesh. ${ }^{3}$ Professor, Department of DVL, GSL Medical College and General Hospital, Rajahmahendravaram, East Godavari, Andhra Pradesh, India. ${ }^{4}$ Professor, Department of DVL, GSL

Medical College and General Hospital, Rajahmahendravaram, East Godavari, Andhra Pradesh, India.
\end{abstract}

\section{ABSTRACT}

\section{BACKGROUND}

Obesity is the accumulation of excess adipose tissue in the body to an extent that it impairs both physical and psychosocial health affecting nearly every system of the body. We wanted to study the prevalence of dermatological manifestations of obesity, their relationship with Body Mass Index (BMI), the prevalence, age and sex distribution.

\section{METHODS}

This study included two hundred new consecutive patients 18 years and above, attending the OPD of Department of DVL at a tertiary centre from August 2018 to June 2019, with BMI of more than 30 kilograms per square meter, waist circumference of $>90$ centimeters $(\mathrm{cm})$ in males and $>80 \mathrm{~cm}$ in females. Pregnant/lactating patients and immunocompromised patients were excluded. A detailed history and a thorough general and systemic examination were done.

\section{RESULTS}

There was a male preponderance with 111 male patients and 89 female patients, the male to female ratio being 1.24:1. Most of the patients (28.00\%) belonged to 51 60 years age group. The mean age of the study group was 56. Most of the patients were farmers (35.50\%). Most of the patients belonged to Grade-I obesity. Hyperinsulinaemia was seen in $89.50 \%$. Diabetes, hypertension and hypothyroidism were seen in $25.00 \%, 21.00 \%$ and $12.50 \%$ respectively. Raised lipid profile was seen in 37 patients $(18.50 \%)$. Many patients had multiple conditions. The most common disorders in our study was acanthosis nigricans $(83.50 \%)$, followed by skin tags $(72.00 \%)$, stretch marks $(70.50 \%)$, dermatophytosis $(36.00 \%)$, acne vulgaris (31.00\%), patterned hair loss (30.50\%). Lupus vulgaris (2.00\%), molluscum contagiosum (1.50\%), verruca vulgaris $(1.50$ $\%)$, lymphoedema (1.00\%), scrofuloderma ( $0.50 \%)$, pemphigus vulgaris $(0.50 \%)$ and lipodermatosclerosis $(0.50 \%)$ were seen in the least number of patients. Hirsutism was seen in 43 patients ( $48.31 \%$ of female patients and $21.50 \%$ of total patients).

\section{CONCLUSIONS}

This study highlights the magnitude of the effect obesity has on the skin. The clinicians should consider BMI evaluation and waist and hip measurements as a crucial component of any dermatologic examination.

\section{KEY WORDS}

Obesity, Dermatological Manifestations, Cutaneous Manifestations, Acanthosis Nigricans, Pemphigus Vulgaris

\author{
Corresponding Author: \\ Dr. Sandeep Kodali, \\ Department of DVL, \\ GSL Medical College and General Hospital, \\ NH-16, Lakshmipuram, Rajanagaram, \\ Rajahmahendravaram, \\ East Godavari District-533296, \\ Andhra Pradesh, India. \\ E-mail: sandeep_kodali@yahoo.com
}

DOI: $10.14260 /$ jemds/2019/618

Financial or Other Competing Interests: None.

How to Cite This Article:

Katta TP, Kodali MP, Kodali S, et al. A clinical study on cutaneous manifestations of obesity. J. Evolution Med. Dent. Sci. 2019;8(37):2846-2849, $10.14260 /$ jemds $/ 2019 / 618$

Submission 25-07-2019,

Peer Review 04-09-2019,

Acceptance 09-09-2019,

Published 16-09-2019. 


\section{BACKGROUND}

Obesity is the accumulation of excess of adipose tissue in the body to an extent that impairs both physical and psychosocial health and wellbeing. It is often frequently neglected, and it is not even thought of as a disease; but obesity is one of the most important, yet preventable health hazard. There is alarming increase in obesity in both developed and developing countries. It causes multitude of skin changes. Prevalence of obesity changes with age, sex, socioeconomic status. ${ }^{1}$ Obesity has multiple effects on nearly every system of the body, which causes a concomitant increase in the mortality and in many of the co-morbidities associated with obesity, many of which are seen less frequently in persons with normal body weight. ${ }^{1,2}$ There has been an increase in dermatologic conditions seen in this special patient population. The skin maladies seen with increased frequency in obese patients are caused by a variety of factors, specifically: the mechanical changes associated with increased weight; the hyperandrogenism of obesity; and the secondary hyperinsulinemia of obesity. ${ }^{2}$

We wanted to study the prevalence, age and sex distribution of dermatological manifestations of obesity and their relationship with Body Mass Index (BMI).

\section{METHODS}

This is a descriptive study of new patients attending the outpatient department of Dermatology, Venereology and Leprosy at a tertiary centre from August 2018 to June 2019.

\section{Inclusion Criteria}

All patients 18 years and above, attending the OPD of the department of Dermatology, Venereology and Leprosy, having a body mass Index (BMI) more than 30 kilograms per square meter attending the dermatology outpatient clinic were included or a waist circumference $>90$ centimeters (cm) on males and $>80 \mathrm{~cm}$ in females.

\section{Exclusion Criteria}

Pregnancy, Lactation. immunocompromised state (present or past history of malignancy, HIV, AIDS)

\section{Methodology}

A detailed history including age, occupation, duration of the disease and site of involvement was taken. A thorough general and systemic examination was done including the anthropometry measurements like weight in kilograms, height in meters, waist circumference in centimeters (At the level of the umbilicus) and hip measurements (At the level of the widest part of the buttocks). Body Mass Index (BMI) was calculated by using the following formula:

$$
\text { BMI }=\frac{\text { Weight }(\text { KG) }}{\text { Height } * \text { Height (Meter } 2)}
$$

Dermatological examination with respect to the morphology, site and distribution of the lesions were done. Investigations like complete blood picture, blood sugars (to diagnose/manage glucose intolerance, diabetes), glycosylated haemoglobin, thyroid profile, fasting insulin levels and fasting lipid profile were done in all patients. Ultrasound Examination of abdomen and pelvis was done in all female patients to observe for polycystic ovaries. Gram's stain, potassium hydroxide (KOH) mount, Tzanck's smear, culture and sensitivity of organisms were done wherever necessary. All the data was recorded, tabulated and analysed.

\begin{tabular}{|c|c|}
\hline Grade & BMI \\
\hline Grade-1 (Mild) & $30-34.9$ \\
\hline Grade-2 (Moderate) & $35-39.9$ \\
\hline Grade-3 (Morbid) & 40.0 and above \\
\hline Table 1. Obesity (BMI > $\mathbf{3 0} \mathbf{~ K g} / \mathbf{m}^{2}$ ) is Graded/ \\
Classified Based on the BMI into 3 Grades \\
\hline
\end{tabular}

\section{RESULTS}

A total of two hundred consecutive patients attending the outpatient department of Dermatology, Venereology and Leprosy from August 2018 to June 2019 were included in the study. There was a male preponderance with 111 male patients and 89 female patients, the male to female ratio being $1.24: 1$. Most of the patients $(28.00 \%)$ belonged to 51 60 years age group with a ratio 1.8 , followed by $41-50$ years age group with a ratio of 0.94 . (Table-2) The mean age of the study group was 56 .

\begin{tabular}{|c|c|c|c|}
\hline Gender & Male & Female & Total \\
\hline $18-30$ Years (Number/Percentage) & $9(4.50 \%)$ & $11(5.50 \%)$ & $20(10.00 \%)$ \\
\hline $31-40$ Years (Number/Percentage) & $13(6.50 \%)$ & $15(7.50 \%)$ & $28(14.00 \%)$ \\
\hline $41-50$ Years (Number/Percentage) & $17(8.50 \%)$ & $18(9.00 \%)$ & $35(17.50 \%)$ \\
\hline $51-60$ Years (Number/Percentage) & $36(18.00 \%)$ & $20(10.00 \%)$ & $56(28.00 \%)$ \\
\hline $61-70$ Years (Number/Percentage) & $18(9.00 \%)$ & $12(6.00 \%)$ & $30(15.00 \%)$ \\
\hline $71-80$ YEARS (Number/Percentage) & $11(5.50 \%)$ & $8(4.00 \%)$ & $19(9.50 \%)$ \\
\hline$>80$ Years (Number/Percentage) & $7(3.50 \%)$ & $5(2.50 \%)$ & $12(6.00 \%)$ \\
\hline Total & \multicolumn{3}{|c|}{\begin{tabular}{|l|l|l|}
$111(55.50 \%)$ & $89(44.50 \%)$ & $200(100.00 \%$ \\
\end{tabular}} \\
\hline
\end{tabular}

BMI was calculated by dividing the weight in kilograms with square of height in meter square. Patients were categorised based on WHO classification into three grades of obesity, based on the BMI. A value of $30-34.99$ was classified into Grade I, from 35.00 to 39.99 as Grade II and more than 40 as Grade III. Most of the patients (145 patients - $72.50 \%$ ) belonged to Grade 1 obesity, followed by Grade 2 obesity (50 patients $-25.00 \%$ ) whereas Grade 3 obesity had the least number (5 patients - $2.50 \%$ ). (Table-3) Based on Waist-Hip Ratio, males with obesity were 108 in number and females 92 , the male is to female ratio being 1.17 .

\begin{tabular}{|c|c|c|c|c|}
\hline Grade of Obesity & \multirow{2}{*}{ Grade 1 } & Grade 2 & Grade 3 & Total \\
\hline Males (Number/Percentage) & $82(41.00 \%)$ & $27(13.55 \%)$ & $2(1.00 \%)$ & $111(55.55 \%)$ \\
\hline Females (Number/Percentage) & $63(31.50 \%)$ & $23(11.50 \%)$ & $3(1.50 \%)$ & $089(44.50 \%)$ \\
\hline Total (Number/Percentage) & $145(72.50 \%)$ & $50(25.00 \%)$ & $5(2.50 \%)$ & $200(100.00 \%)$ \\
\hline Table 3. Distribution of Patients Based on Gender and Grades of \\
Obesity Based on Body Mass Index \\
\hline
\end{tabular}

Based on occupation, most of the patients were farmers $(35.50 \%)$, followed by teachers $(17.00 \%)$ and homemakers (16.50\%). Anganwadi workers (1.50\%), bank employees $(1.00 \%)$ and priest $(0.50 \%)$ were the least among the patients of obesity (Table 4). 


\begin{tabular}{|c|c|c|c|}
\hline Occupation & Males & Females & Total \\
\hline Farmers & $52(26.00 \%)$ & $19(9.50 \%)$ & $71(35.50 \%)$ \\
\hline Teachers & $11(5.50 \%)$ & $23(11.50 \%)$ & $34(17.00 \%)$ \\
\hline Housewives & $\mathrm{N} / \mathrm{A}$ & $33(16.50 \%)$ & $33(16.50 \%)$ \\
\hline Drivers & $27(13.50 \%)$ & NIL & $27(13.50 \%)$ \\
\hline Retired & $10(5.00 \%)$ & $2(1.00 \%)$ & $12(6.00 \%)$ \\
\hline Students & $7(3.50 \%)$ & $4(2.00 \%)$ & $11(5.50 \%)$ \\
\hline Nurses & $1(0.50 \%)$ & $5(2.50 \%)$ & $6(3.00 \%)$ \\
\hline Anganwadi workers & N/A & $3(1.50 \%)$ & $3(1.50 \%)$ \\
\hline Bank employee & $2(1.00 \%)$ & 0 & $2(1.00 \%)$ \\
\hline Priest & $1(0.50 \%)$ & 0 & $1(0.50 \%)$ \\
\hline Total & $111(55.50 \%)$ & $89(44.50 \%)$ & $200(100.00 \%)$ \\
\hline \multicolumn{4}{|c|}{ Table 4. Distribution of Patients Based on Gender and Occupation } \\
\hline
\end{tabular}

Hyperinsulinaemia was seen in 97 males $(87.38 \%$ of male patients, $48.50 \%$ out of the total number of patients) and $82(92.13 \%$ of total female patients, $41.00 \%$ of total number of patients) female patients, a total of 179 patients (89.50\%). Diabetes was seen in 27 males (24.32\% of all male patients and $13.50 \%$ of total patients), whereas it was seen in 23 females $(25.84 \%$ of total female patients and $11.50 \%$ of total number of patients), a total of 50 patients $(25.00 \%)$. Forty-two patients $(21.00 \%)$ had hypertension. Hypothyroidism was seen in 9 male patients $(8.10 \%$ of male patients and $4.50 \%$ of total number of patients) and 16 female patients $(17.97 \%$ of female patients and $8.00 \%$ of total number of patients), making a total of 25 patients $(12.50$ $\%)$. Raised lipid profile was seen in 23 male patients $(27.71$ $\%$ of male patients, $11.50 \%$ of total number of patients) while the female patients with raised lipid profile were 14 (20.89\% of all female patients and $7.00 \%$ of the total number of patients). Polycystic Ovarian Disease was seen in 22 out of 89 females in the study.

In our study, 200 cases were included, many of whom had multiple conditions (Table 5). The most common disorder in our study was acanthosis nigricans (167 patients - $83.50 \%$ ). It was seen mainly in the neck, followed by axillae and antecubital fossae. The next common disorder in our study was skin tags (72.00\%), again seen commonly in the neck, followed by axillae and the waist. Stretch marks (70.50\%) were seen in on the abdomen and waist, thighs, shoulders and chest, buttocks and thighs in that order. Dermatophytosis was seen in $36.00 \%$ of the patients involving the thighs, genitalia, buttocks, pubic area, lower abdomen, face and axillae in that order. Acne vulgaris was seen $31.00 \%$ of the patients followed by patterned hair loss $(30.50 \%)$. Lupus vulgaris (2.00\%), molluscum contagiosum (1.50\%), verruca vulgaris $(1.50 \%)$, lymphoedema (1.00\%), scrofuloderma $(0.50 \%)$, pemphigus vulgaris $(0.50 \%)$ and lipodermatosclerosis $(0.50 \%)$ were seen in least number of patients. Hirsutism was seen in 43 patients $(48.31 \%$ of female patients and $21.50 \%$ of total patients).

\begin{tabular}{|c|c|c|c|c|}
\hline Sl. No. & Disease & Males & Females & Total \\
\hline 1 & Acanthosis Nigricans & 89 & 78 & $167(83.50 \%)$ \\
\hline 2 & Acrochordons & 76 & 68 & $144(72.00 \%)$ \\
\hline 3 & Stretch Marks & 86 & 55 & $141(70.50 \%)$ \\
\hline 4 & Dermatophytosis & 34 & 38 & $72(36.00 \%)$ \\
\hline 5 & Acne Vulgaris & 28 & 34 & $62(31.00 \%)$ \\
\hline 6 & Patterned hair loss & 31 & 30 & $61(30.50 \%)$ \\
\hline 7 & Hirsutism & N/A & 43 & $43(21.50 \%)$ \\
\hline 8 & Plantar keratoderma & 23 & 15 & $38(19.00 \%)$ \\
\hline 9 & Facial hypermelanosis & 25 & 13 & $38(19.00 \%)$ \\
\hline 9 & Keratosis pilaris & 18 & 16 & $34(17.00 \%)$ \\
\hline 10 & Furunculosis & 18 & 15 & $33(16.50 \%)$ \\
\hline 11 & Herpes zoster & 20 & 11 & $31(15.50 \%)$ \\
\hline 12 & Intertrigo & 10 & 15 & $25(12.50 \%)$ \\
\hline 13 & Hidradenitis suppurativa & 14 & 6 & $20(10.00 \%)$ \\
\hline 14 & Scabies & 10 & 5 & $15(7.50 \%)$ \\
\hline
\end{tabular}

\begin{tabular}{|l|c|c|c|c|}
\hline 15 & Erythrasma & 5 & 6 & $11(5.50 \%)$ \\
\hline 16 & Lupus vulgaris & 2 & 2 & $4(2.00 \%)$ \\
\hline 17 & Molluscum contagiosum & 2 & 1 & $3(1.50 \%)$ \\
\hline 18 & Verruca vulgaris & 1 & 2 & $3(1.50 \%)$ \\
\hline 19 & Lymphoedema & 1 & 1 & $2(1.00 \%)$ \\
\hline 20 & Scrofuloderma & 0 & 1 & $1(0.50 \%)$ \\
\hline 21 & Pemphigus vulgaris & 1 & 0 & $1(0.50 \%)$ \\
\hline 22 & Lipodermatosclerosis & 0 & 1 & $1(0.50 \%)$ \\
\hline \multicolumn{6}{|c|}{ Table 5. Dermatoses and the Number of Patients Seen in our Study } \\
\hline
\end{tabular}

\section{DISCUSSION}

The age of the patients in our study ranged from 18 to 85 years with maximum number of patients belonging to the age group of 51-60 years (28.00\%), followed by $41-50$ years $(17.50 \%)$ age group. This was not in concordance with other studies, where the majority of the patients fell in the age group of 21-40 years.3,4,5 The mean age of the study group was 56 , which was in concordance with a study by Sivakumar S et al. ${ }^{4}$

In our study, there were 111 (55.50\%) males and 89 $(44.50 \%)$ females with a male to female ratio of $1.24: 1$. The higher percentage of male patients in this study can be explained that in rural India, female patients may be hesitant to consult a doctor for examination. A decreasing trend in the percentage of female patients was observed with increase in age. This may be due to the reason that young females are more concerned about their appearance and body image than their elder counterparts. Most of the subjects were farmers and coolies (35.50\%), followed by teachers $(17.00 \%)$ and housewives (16.50\%).

Most of our patients (72.50\%) belonged to Grade I Obesity, followed by Grade II Obesity (25.00\%) and lastly Grade III Obesity (2.50 \%). Various studies ${ }^{4,5,6}$ showed similar predominance of Grade I Obesity, but our study tallied with the study done by Palanisamy RP et $\mathrm{al}^{5}$ (75.74 \%).

Hyperinsulinaemia was seen in 97 males $(87.38 \%$ of male patients, $48.50 \%$ out of the total number of patients) and $82(92.13 \%$ of total female patients, $41.00 \%$ of total number of patients) female patients, a total of 179 patients $(89.50 \%)$. Obesity is regarded as a hyperinsulinaemic state in which increased levels of circulating insulin leads to decreased numbers of functional/classic insulin receptors which are involved in glucose uptake, cell growth, DNA synthesis and protein and fat metabolism via tyrosine kinase activity. Decreased numbers of functional insulin receptors cause a shift towards increased binding with insulin-like growth factor (IGF) receptors, expressed over the surface of keratinocytes and fibroblasts, contributing to the development of acanthosis nigricans due to growth promoting effects. ${ }^{3}$

Acanthosis nigricans $(83.50 \%)$ is the most common cutaneous finding in our study. This was in similar to other studies done by Naik KH et al, ${ }^{1}$ Shareef $\mathrm{RA}^{\mathrm{K}}$ et $\mathrm{al}^{5}$ and Sivakumar et $\mathrm{al}^{4}$ who found the incidence to be $64.44 \%, 95$ $\%$ and $65.00 \%$ respectively. Neck was the common area to be involved in acanthosis, followed by axilla. But it was in contrast with a study by Palanisamy RP, 6 wherein acrochordons (26.6\%) were the most common finding. In our study, skin tags $(72.00 \%)$ were the second common. This was in correlation with one study by Naik $\mathrm{KH}$ et $\mathrm{al}^{2}{ }^{2}$ but it differed in percentage (46.6\%). Other studies ${ }^{5}$ showed acrochordons to be $3^{\text {rd }}$ common dermatoses respectively. Striae distensiae was the third most common dermatosis in 
our study, seen in $70.50 \%$ of the subjects, similar to another study $(72.00 \%), 5$ but it was the $2^{\text {nd }}$ most common dermatoses in that study.

Dermatophytosis $(36.00 \%)$ was the next common dermatosis in our study, which was in concordance (37.33\%) with a study by S. Arti et al. ${ }^{3}$

Dermatological manifestations of hyperandrogenism such as androgenetic alopecia, acne and hirsutism were seen in 31 $\%, 30.50 \%$ and $21.5 \%$ of patients in our study. S Arti et al, ${ }^{3}$ in her study, showed the incidence of these manifestations to be $55.67 \%, 28.67 \%$ and $16.67 \%$ respectively. Hirsutism was seen in 43 patients (21.50\%), whereas it was seen in $7.00 \%$ of the patients in a study. ${ }^{5}$ Hyperandrogenism in obesity is attributed to adipose tissue, which converts testosterone to dihydrotestosterone, and hyperinsulinaemia which is commonly seen in obesity. Hyperinsulinaemia leads to increased production of ovarian androgens and insulin also inhibits the synthesis of sex hormone binding globulins, thereby increasing the free testosterone in the blood, leading to more severe form of hyperandrogenism. ${ }^{3}$

The most common comorbidity seen in our study were diabetes (25.00\%) followed by hypertension (21.00\%) and hypothyroidism (12.50\%). A study by S. Arti et al ${ }^{3}$ showed that the incidence was $18 \%, 7 \%$ and $10 \%$ respectively. A study done by Raja Shareef et $\mathrm{al}^{5}$ showed that $22.00 \%$ and $15.00 \%$ of the subjects had diabetes and hypertension respectively. Altered lipid profile was seen in $18.50 \%$ of our patients.

\section{CONCLUSIONS}

This study highlights the magnitude of the effect obesity has on the skin. Not only does the mechanical force created by the obese patient's extra weight cause a host of conditions, but the endocrinologic abnormalities associated with obesity can cause a variety of other skin diseases. The effect obesity has on the skin is so significant that many of the above mentioned conditions can occur in patients without any other identifiable risk factors. This fact alone should cause clinicians to consider BMI evaluation and waist and hip measurements as a crucial component of any dermatologic examination.

\section{REFERENCES}

[1] Naik KH, Nageswarammamd S. Skin - a mirror reflecting underlying obesity. IOSR J Den Med Sci 2016;15(8):44-7.

[2] Waldman RA, Kettler AH. Dermatologic manifestations of obesity: Part I mechanical causes. J Obes \& Weight-Loss Medic 2016;2(1):010.

[3] Arti S, Gupta V, Dogra D. A hospital-based clinical study of cutaneous changes in overweight and obesity. Int J Health Sci Res 2017;7(6):56-64.

[4] Sivakumar S, Banupriya K. A cross-sectional descriptive clinical study of dermatological manifestations in obesity. Int J Res Dermatol 2017;3(3):337-41.

[5] Shareef RA, Prasad PVS, Kaviarasan PK. Cutaneous markers of obesity. Int J Res Med Sci 2018;6(11):3562-6.

[6] Palanisamy RP, Selvaraj S, Sikkanthar SI, et al. A clinical study on the dermatological manifestations of obesity at a tertiary care centre in Coimbatore. J Evid Based Med Healthc 2016;3(58):3070-3. 